\title{
Cytotoxicity of 6-Mercaptopurine via Loading on PVA-Coated Magnetite Nanoparticles Delivery System: A New Era of Leukemia Therapy
}

Moustafa ME, Amin AS and Magdi $Y^{*}$

Chemistry Department, Faculty of Science, Benha University, Benha, Egypt

\begin{abstract}
$\mathrm{Fe}_{3} \mathrm{O}_{4}$ were synthesized via chemical co-precipitation method in which $\mathrm{NH}_{4} \mathrm{OH}$ acted as reducing agent to obtain water-dispersible, biocompatible, magnetite $\left(\mathrm{Fe}_{3} \mathrm{O}_{4}\right)$ nanoparticles. The latters were coated with polyvinyl alcohol (PVA) and 6-Mercaptopurine (6-MP) drug was then loaded into the surface of PVA-coating- $\mathrm{Fe}_{3} \mathrm{O}_{4}$ nanoparticles. The structural, morphological and magnetic characterization of the uncoated, coated and 6-MP loaded iron oxide nanoparticles are presented here. The particles were characterized by XRD, HR-TEM, TGA, FTIR and vibrating sample magnetometer (VSM). Cytotoxicity of 6-Mercaptopurine loaded into PVA-coated magnetite nanoparticles as a new era of leukemia therapy was studied aiming to improve its therapeutic effects by decreasing its dose as well its side effects.
\end{abstract}

Keywords: Magnetite nanoparticles; 6-Mercaptopurine-PVAcoating; Leukemia therapy

\section{Introduction}

Investigation on super paramagnetic iron oxide nanoparticles (SIONPs) is among the most fundamental areas in biomedical field for their various applications such as magnetic hyperthermia, targeted drug delivery, biosensing and magnetic resonance imaging applications [1-5]. Targeted drug delivery via magnetic iron oxide nanoparticles has been explored extensively in the hope of improving the efficacy of chemotherapy and reducing its toxicity and adverse side effects [6-10]. Magnetic iron oxide nanoparticles possess a high potential to incorporate with drugs to form a highly efficient drug delivery system as well as a great specificity of drug actions within the target sites only. Various methods can be employed for synthesis magnetite such as physical vapor deposition, electro deposition, chemical vapor deposition, thermal decomposition, hydrothermal, and chemical coprecipitation [11]. Chemical co-precipitation is the most popular applied method for fabrication of $\mathrm{Fe}_{3} \mathrm{O}_{4}$ nanoparticles [12].

The application of uncoated iron oxide nanoparticles is still limited due to their low solubility that can lead to precipitation and high agglomeration rate under physiological conditions [1]. Thus, incorporating magnetic iron oxide nanoparticles into a polymer has been developed for surface functionalization and stabilization. For synthesis of surface functionalized magnetic iron oxide nanoparticles, further co-precipitation of iron oxide with various types of biocompatible and hydrophilic polymers including dextran [5], polyethylene glycols (PEG) [13], polyvinyl alcohol (PVA) [14] and polyvinyl pyrrolidone (PVP) [15] increases the stability, biocompatibility and biodegradability of iron oxide nanoparticles as well as provides the opportunity to modify their surface to create loading sites for carrying drugs.

6-Mercaptopurine (6-MP), a purine analogue, has been effectively used as a therapeutic for the treatment of cancer, especially leukemia [16]. The key mechanism of 6-MP cytotoxicity is that it interferes with nucleic acid synthesis, so treatment with 6-MP might produce cell mutations as well as teratogenic effects for untargeted healthy cells [17]. Moreover, 6-MP influences the development of second malignant neoplasm and increases the rate of relapse. Therefore, further modification and dose adjustment for 6-MP is recommended in order to counteract such genetic predisposition and reduce its side effects [16-18].<smiles>S=c1nc[nH]c2nc[nH]c12</smiles>

6-Mercaptopurine (6-MP), The objective of the present study is to investigate the efficiency of loading 6-MP with PVA-coated magnetite nanoparticles, on improving its therapeutic effect hoping to decrease its dose as well its side effects.

\section{Materials and Methods}

\section{Materials}

Analytical grade chemicals were used in this work without further purification; deionized water was used in all experiments. All glass wares were thoroughly cleaned with aqua regia (3:1 ratio by volume of $\mathrm{HCl}$ and $\mathrm{HNO}_{3}$ ), and then washed several times with distilled water before use. Ferrous chloride tetrahydrate $\left(\mathrm{FeCl}_{2} \cdot 4 \mathrm{H}_{2} \mathrm{O} \geq 99 \%\right.$, Merck KGaA, Darmstadt, Germany), ferric chloride hexahydrate $\left(\mathrm{FeCl}_{3} \cdot 6 \mathrm{H}_{2} \mathrm{O}, 99 \%\right.$, Merck, KGaA, Darmstadt, Germany), polyvinyl alcohol (PVA) (SigmaAldrich; $87-88 \%$ hydrolyzed, $\mathrm{Mw}=13,000-23,000 \mathrm{~mol}^{-1}$ ). All tips and glass wares used in the cytotoxicity studies were sterilized using autoclave and dry heat, and all tested samples were sterilized under UV for 3 hours.

\section{Preparation of uncoated magnetite nanoparticles}

Using a chemical co-precipitation method, iron oxide nanoparticles were synthesized as previously described by Yang et al. [19]. Briefly, the

*Corresponding author: Magdi Y, Chemistry Department, Faculty of Science, Benha University, Benha, Egypt, Tel: 20110124096862; E-mail: dr.moustafa1955@ yahoo.com

Received: October 13, 2018; Accepted: December 10, 2018; Published: December 14, 2018

Citation: Moustafa ME, Amin AS, Magdi Y (2018) Cytotoxicity of 6-Mercaptopurine via Loading on PVA-Coated Magnetite Nanoparticles Delivery System: A New Era of Leukemia Therapy. J Nanomed Nanotechnol 9: 521. doi: 10.4172/21577439.1000521

Copyright: $\odot 2018$ Moustafa ME, et al. This is an open-access article distributed under the terms of the Creative Commons Attribution License, which permits unrestricted use, distribution, and reproduction in any medium, provided the original author and source are credited. 
molar ratio of $\mathrm{Fe}$ (II)/Fe (III) was kept 0.5 by dissolving a mixture of $2.15 \mathrm{~g}$ ferrous (II) chloride tetrahydrate $\left(\mathrm{FeCl}_{2} .4 \mathrm{H}_{2} \mathrm{O}\right)$ and $5.8 \mathrm{~g}$ of ferric (III) chloride hexahydrate $\left(\mathrm{FeCl}_{3} 6 \mathrm{H}_{2} \mathrm{O}\right)$ in $175 \mathrm{~mL}$ of distilled deionized water. After heating the orang colored mixture to $80^{\circ} \mathrm{C}$ under vigorous stirring, $10 \mathrm{~mL}$ of $25 \%$ ammonium hydroxide $\mathrm{NH}_{4} \mathrm{OH}$ solution was added resulting in a black precipitate having $\mathrm{pH}$ of 11 . The resulting magnetite nanoparticles (black precipitate) was then centrifuged and washed with distilled deionized water for 3 times (6 minutes for each wash) to remove all residuals. The black precipitates were collected using a strong permanent magnet, washed, and dried in a vacuum oven at $40^{\circ} \mathrm{C}$ before characterization.

\section{Preparation of PVA-coated magnetite nanoparticles}

The coating of PVA on magnetite was achieved according to the method previously proposed by Kayal et al. [20], with slight modification. Uncoated magnetite nanoparticles were capped with PVA by adding a solution of $4 \%$ PVA (one gram uncoated nanoparticles and 4 gram dry PVA powder in ninety five grams of deionized water, pale orange colored solution) at $80^{\circ} \mathrm{C}$. Complete dissolution of PVA was achieved under vigorous magnetic stirring for $24 \mathrm{~h}$ at room temperature in a given $\mathrm{pH}$ of 7.3. A final 3 times wash (6 minutes for each wash) of PVA-coated magnetite nanoparticles with distilled deionized water was done to remove all excess non-participating PVA polymer. The orange precipitates were collected using a strong permanent magnet, washed, and dried in a vacuum oven at $40^{\circ} \mathrm{C}$ before characterization.

\section{Loading of 6-MP on to PVA-coated magnetite nanoparticles}

The purified PVA-coated magnetite nanoparticles were redispersed in distilled deionized water and left at room temperature. Pure 6-MP was dissolved in hot ethanol with shaking in orbital shaker for 10 minutes. A $2 \%$ of $6-\mathrm{MP}$ solution was added to the PVA-coated magnetite nanoparticles solution, and the mixture was vigorously stirred for 24 hours at room temperature (dark orange to red colored solution). A several times wash with distilled deionized water was performed to remove all non-bounding drug. Finally, the 6-MP loaded PVA-coated magnetite (black precipitate) was collected using a permanent magnet, washed with deionized water 3 times ( 6 minutes for each wash), and dried in an oven.

\section{Characterization}

Fourier transform infrared (FTIR) spectra were recorded on a Jasco FTIR-460 plus, Japan (National Organization for Drug Control and Research (NODCAR); Cairo, Egypt). Powder X-ray diffraction (XRD) pattern was performed with a Bruker-AXS X-ray diffractometer (National Research Centre, Cairo, Egypt) using $\mathrm{Cu}-\mathrm{Ka}$ radiation $(\lambda=$ $1.5406 \AA$ ) under the acceleration voltage of $40 \mathrm{kV}$ and a current of $40 \mathrm{~mA}$. The determination of crystal size, morphology and size distribution of the prepared magnetite nanoparticles, PVA-coated magnetite nanoparticles, and 6-MP-PVA-coated magnetite nanoparticles were performed using JEOL JEM-1230 EM high resolution-transmission electron microscope (HR-TEM) with an acceleration voltage of 200 $\mathrm{kV}$ (Nanotech Company, $6^{\text {th }}$ October city, Cairo, Egypt) equipped with Gatan digital camera Erlangshen ES500. Thermogravimetric analyses (TGA) was carried out using a Perkin Elmer thermogravimetric analyzer, USA (National Research Centre, Cairo, Egypt). The analyses were performed in $150 \mu \mathrm{L}$ alumina crucibles in the temperature range of $25^{\circ} \mathrm{C}-650^{\circ} \mathrm{C}$. Magnetic properties of the samples were investigated through a vibrating sample magnetometer (VSM; 9600-1 LDJ, USA) at room temperature with a maximum magnetic field of $15 \mathrm{kOe}$, where the saturation magnetization $(\mathrm{Ms})$, remanence magnetization $(\mathrm{Mr})$ and coercivity $(\mathrm{Hc})$ were evaluated.

\section{Cytotoxicity studies}

Leukemia cancer cell line, HL-60, was obtained from VACSERA tissue culture unit, Egypt. The cells were passed in Dulbecco's modified Eagle's medium (DMEM) supplemented with 10\% heat-inactivated fetal bovine serum, $1 \% \mathrm{~L}$-glutamine, HEPES buffer and $50 \mu \mathrm{g} / \mathrm{ml}$ gentamycin after thawing. Cells were cultured in at $37^{\circ} \mathrm{C}$ in a humidified incubator containing $5 \% \mathrm{CO}_{2}$ in room air to be used for seeding after reaching $90 \%$ confluence.

Culture plates were seeded then in 96-well plate with HL-60 at concentration of $1 \times 10^{4}$ cells/ per well in $100 \mu \mathrm{l}$ of growth medium and cultured for 24 hours in the $5 \% \mathrm{CO}_{2}$ incubator. The culture media was then replaced with the different prepared samples of magnetite nanoparticles, PVA-coated magnetite nanoparticles, and 6-MP-PVAcoated magnetite nanoparticles with labeling the wells. The cells were then incubated for 24 hours to be measured. Three wells were used for each concentration of the test sample. Wells left with cells without test sample and with or without DMSO were considered as control.

Colorimetric assay was performed to measure the cytotoxicity of prepared samples. In brief, media were aspirated and the crystal violet solution (1\%) was added to each well and left in $5 \% \mathrm{CO}_{2}$ incubator for at least 30 minutes at $37^{\circ} \mathrm{C}$. The stain was removed and the plates were rinsed using tap water with shaking until all excess stain was removed. Glacial acetic acid (30\%) was then added to all wells and mixed thoroughly, and then the absorbance of the plates were measured after gently shaken on Microplate reader (TECAN, Inc.), at a wavelength of $490 \mathrm{~nm}$.

The results of the cell cytotoxic effect of each tested compound were calculated. The percentage of cell viability was calculated as $\left[1-\left(\mathrm{O}_{\mathrm{Dt}}\right)\right.$ $\left.\left.\mathrm{O}_{D c}\right)\right] \times 100 \%$ where $\mathrm{O}_{\mathrm{Dt}}$ is the mean optical density of wells treated with the tested sample and $\mathrm{O}_{\mathrm{Dc}}$ is the mean optical density of control sample that represents $100 \%$ viability. The relation between surviving cells and drug concentration was plotted to get the survival curve of each tumor cell line after treatment with the specified compound. The $50 \%$ inhibitory concentration $\left(\mathrm{IC}_{50}\right)$, the concentration required to cause toxic effects in $50 \%$ of intact cells, was estimated from graphic plots of the dose response curve for each concentration.

\section{Results and Discussion}

In the present study we aimed to load 6-MP into the surface of PVAcoated- $\mathrm{Fe}_{3} \mathrm{O}_{4}$ nanoparticles. The efficiency of loaded 6-MP as a new era of leukemia therapy was studied aiming to decrease its dose as well as its side effects. $\mathrm{Fe}_{3} \mathrm{O}_{4}$ were synthesized via chemical co-precipitation method in which $\mathrm{NH}_{4} \mathrm{OH}$ acted as reducing agent and then coated with PVA. The structural, morphological and magnetic characterization of the prepared nanoparticles is also presented here.

\section{Structural and morphological properties}

XR diffraction: The powder XRD patterns of uncoated $\mathrm{Fe}_{3} \mathrm{O}_{4}$, PVA coated $\mathrm{Fe}_{3} \mathrm{O}_{4}$ and 6-MP-PVA-coated $\mathrm{Fe}_{3} \mathrm{O}_{4}$ nanoparticles are presented in Figure 1. From the XRD analysis, all the prepared samples are polycrystalline with broad diffraction peaks. Uncoated $\mathrm{Fe}_{3} \mathrm{O}_{4}$ showed six broad characteristic diffraction peaks $\left(2 \nabla=30^{\circ}, 35.4^{\circ}, 43^{\circ}\right.$, $53.4^{\circ}, 56.9^{\circ}$ and $62.5^{\circ}$ ) correspond to pure iron oxide with a standard pattern of face centered cubic (fcc) inverse spinel structure. Absence of (210) and (300) diffraction peaks in the XRD pattern indicates the absence of maghemite $\left(\gamma-\mathrm{Fe}_{2} \mathrm{O}_{3}\right)$ in the prepared sample. The same six characteristic peaks are observed in both samples (Figure 1), confirming that the coating process did not affect any phase change in $\mathrm{Fe}_{3} \mathrm{O}_{4}$ nanoparticles. An observed spontaneous broadening in the peaks of 

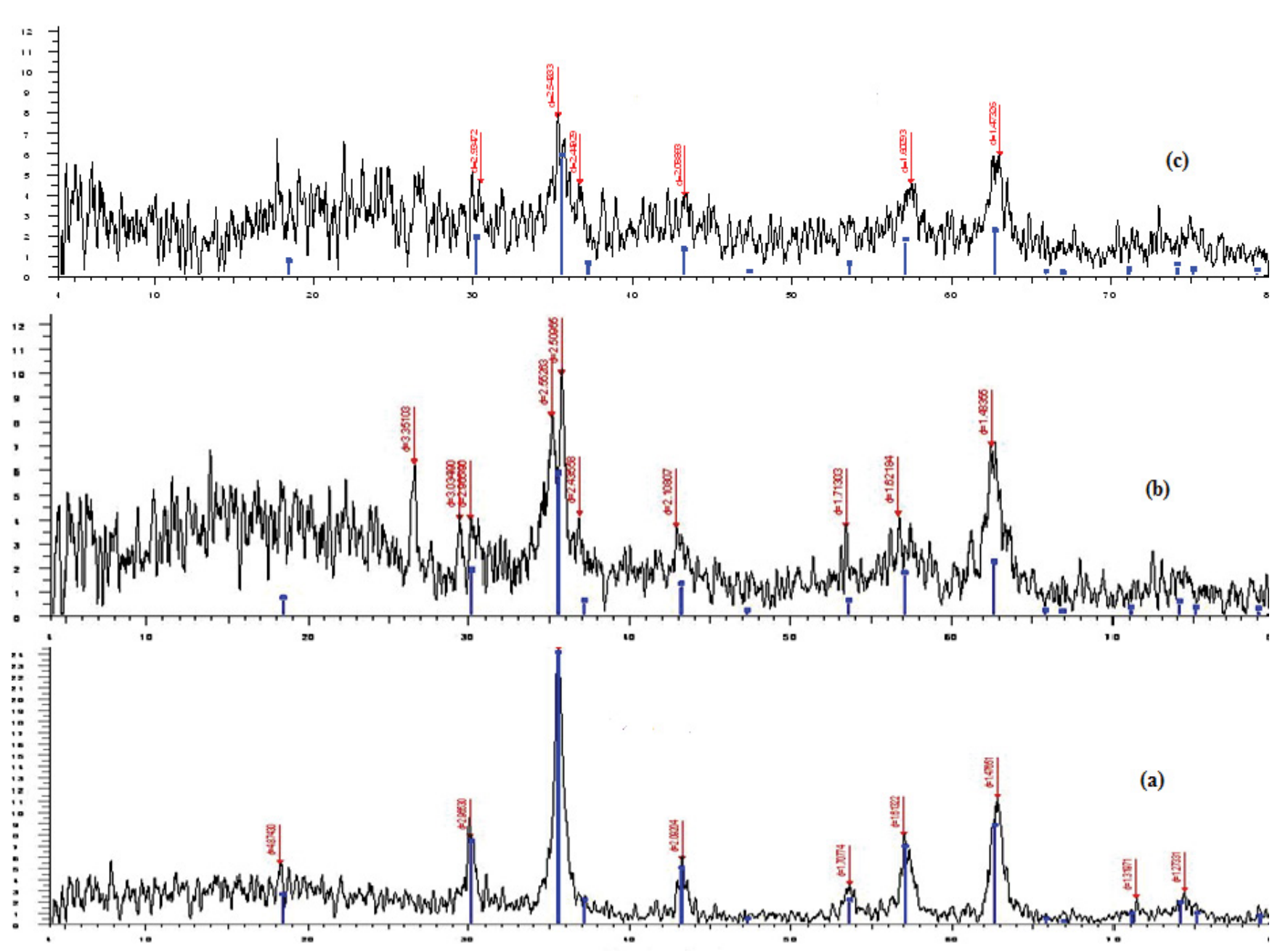

Figure 1: The XRD patterns of (a) $\mathrm{Fe}_{3} \mathrm{O}_{4}$ (b) PVA-coated $\mathrm{Fe}_{3} \mathrm{O}_{4}$ nanoparticles and (c) 6-MP-PVA-coated-Fe $\mathrm{O}_{4}$ nanoparticles.

ing that the coating process did not affect any phase change in $\mathrm{Fe}_{3} \mathrm{O}_{4}$ nanoparticles. An observed spontaneous broadening in the peaks of PVA coated iron oxide and 6-MP loaded onto PVA-coated magnetite nanoparticles corresponding the decrease in crystalline size, which confirming the coating of PVA onto $\mathrm{Fe}_{3} \mathrm{O}_{4}$ nanoparticles followed by loading of 6-MP on their surface. The XRD results agree well with those previously reported [21,22].

High resolution transmittance electron microscope: HRTEM was further used to obtain more information about the size and uniformity of the synthesized complexes in details. HR-TEM micrographs and electron diffraction of uncoated $\mathrm{Fe}_{3} \mathrm{O}_{4}$ nanoparticles are shown in Figure 2. Uncoated $\mathrm{Fe}_{3} \mathrm{O}_{4}$ appears spherical shape with narrow particle size distribution $(\sim 10 \mathrm{~nm})$. Otherwise, selective area electronic diffraction pattern (SAED) indicated the polycrystalline nature of these $\mathrm{Fe}_{3} \mathrm{O}_{4}$ nanoparticles (inset of Figure 2D). As shown in Figure 2 some uncoated $\mathrm{Fe}_{3} \mathrm{O}_{4}$ had formed clusters, this is in accordance to previous observation made by Gupta et al. [23]. This is proposed to be due to the absence of coating materials in the presence of aerobic conditions during their synthesis could enhance the hydrophobic interactions between the particles, thereby agglomerating them to form some clusters. After coating $\mathrm{Fe}_{3} \mathrm{O}_{4}$ nanoparticles with PVA, HR-TEM images in Figure 3 shows polydispersed particles with agglomeration attributed to magnetic dipole-dipole attractions between the particles, as observed in the $\mathrm{Fe}_{3} \mathrm{O}_{4}$ nanoparticles. Figure 4 Shows HR-TEM images of 6-Mercaptopurine loaded PVA-coated $\mathrm{Fe}_{3} \mathrm{O}_{4}$ nanoparticles with blurring film, confirming the loading of the drug onto the PVA-coated $\mathrm{Fe}_{3} \mathrm{O}_{4}$ surface.

FTIR spectra: FTIR was further performed within the wavelength range $4000-600 \mathrm{~cm}^{-1}$ to examine the mode of attachment of the PVA to the $\mathrm{Fe}_{3} \mathrm{O}_{4}$ and conjugation of 6-MP anticancer drug with the PVA coated $\mathrm{Fe}_{3} \mathrm{O}_{4}$. The most important IR spectral bands frequencies $\left(\mathrm{cm}^{-1}\right)$ were assigned according to Smith [24] and are cited in Table 1. Inspection of the IR spectral data shows that:

- The broad band of uncoated $\mathrm{Fe}_{3} \mathrm{O}_{4}$ and PVA-coated- $\mathrm{Fe}_{3} \mathrm{O}_{4}$ at 590 and $580 \mathrm{~cm}^{-1}$, respectively, is attributed to the stretching vibration of $(\mathrm{M})$ of $\mathrm{Fe}_{\mathrm{td}}-\mathrm{O}-\mathrm{Fe}_{\mathrm{Oh}}$, where $\mathrm{Fe}_{\mathrm{td}}$ and $\mathrm{Fe}_{\mathrm{Oh}}$ correspond to the iron occupying the tetrahedral and octahedral positions, respectively [25].

- The broad bands of pure 6-MP at 1615 and $1405 \mathrm{~cm}^{-1}$ are assigned to the stretching vibration frequency of $\mathrm{C}-\mathrm{C}$ group $(v$ $\mathrm{C}=\mathrm{C})$ and the stretching vibration of $\mathrm{C}-\mathrm{N}$ group $(v \mathrm{C}-\mathrm{N})$, 
Citation: Moustafa ME, Amin AS, Magdi Y (2018) Cytotoxicity of 6-Mercaptopurine via Loading on PVA-Coated Magnetite Nanoparticles Delivery System: A New Era of Leukemia Therapy. J Nanomed Nanotechnol 9: 521. doi: 10.4172/2157-7439.1000521
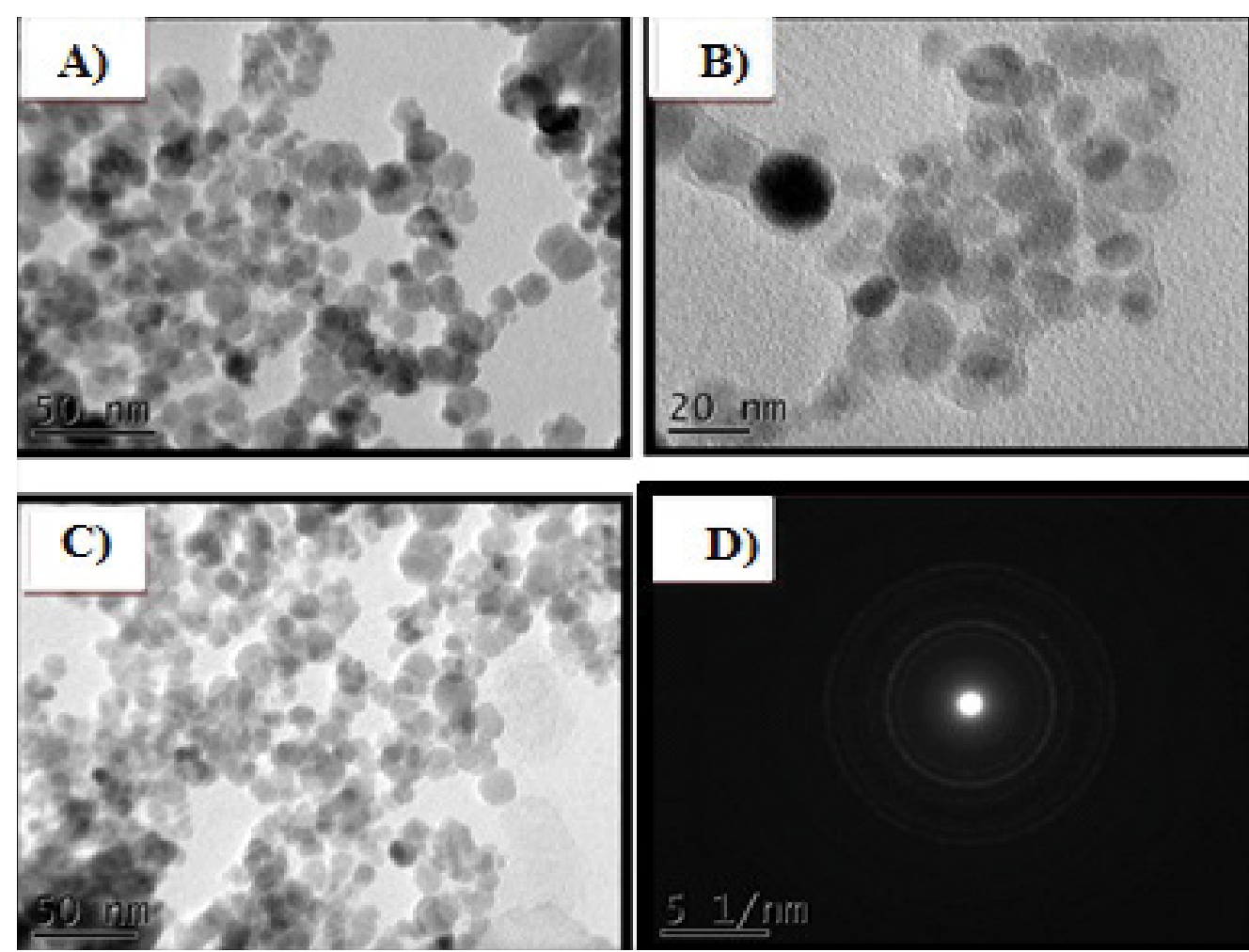

Figure 2: HR-TEM image from different spots with different magnification scales of the prepared $\mathrm{Fe}_{3} \mathrm{O}_{4}$ nanoparticles; $(\mathrm{a}, \mathrm{b}$ and $\mathrm{c})$ and their selective area electronic diffraction pattern (SAED) (d).
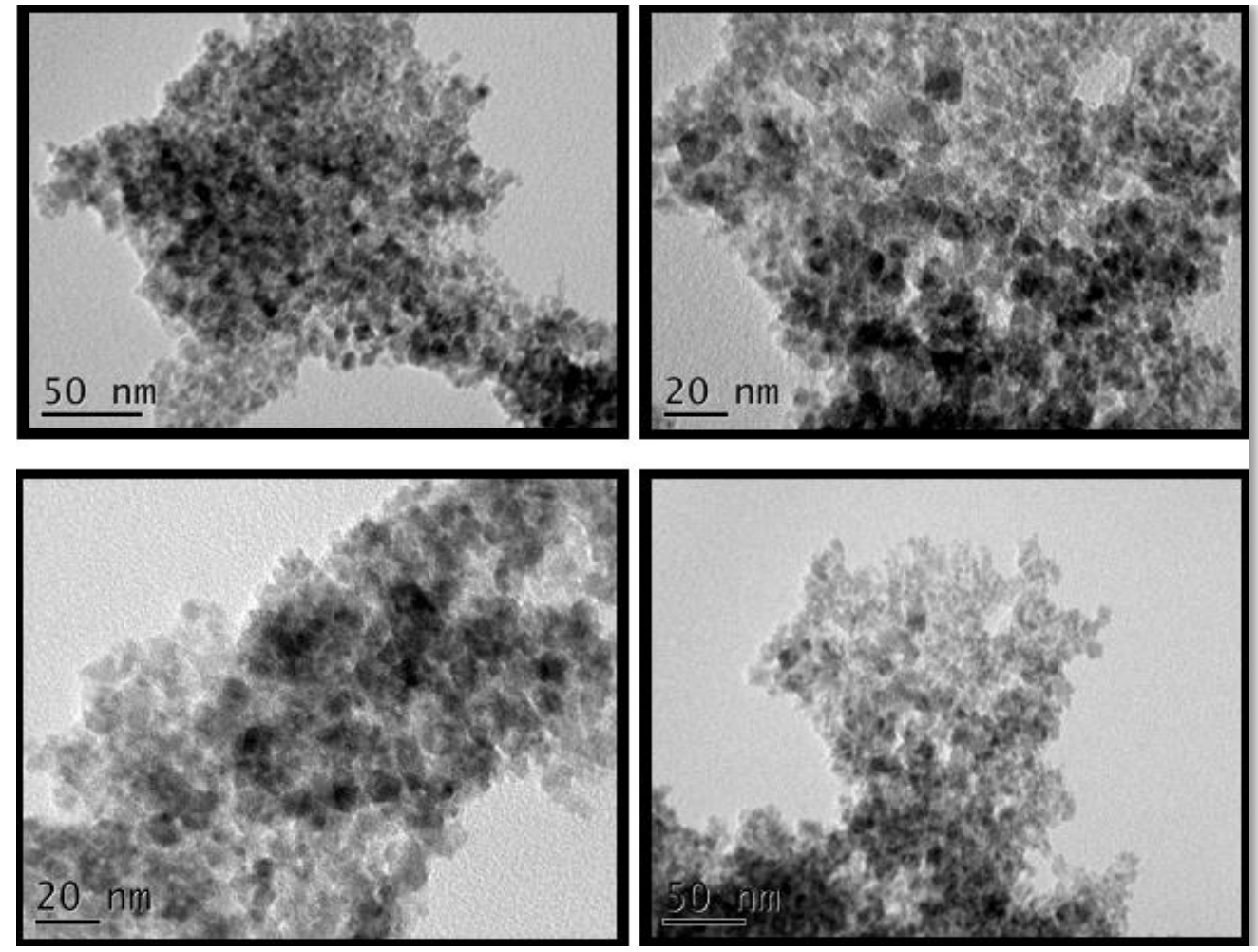

Figure 3: The HR-TEM images from different spots with different magnification scales of PVA coated $\mathrm{Fe}_{3} \mathrm{O}_{4}$ nanoparticles. 
Citation: Moustafa ME, Amin AS, Magdi Y (2018) Cytotoxicity of 6-Mercaptopurine via Loading on PVA-Coated Magnetite Nanoparticles Delivery System: A New Era of Leukemia Therapy. J Nanomed Nanotechnol 9: 521. doi: 10.4172/2157-7439.1000521

PVA coated iron oxide and 6-MP loaded onto PVA-coated magnetite nanoparticles corresponding the decrease in crystalline size, which confirming the coating of PVA onto $\mathrm{Fe}_{3} \mathrm{O}_{4}$ nanoparticles followed by loading of 6-MP on their surface. The XRD results agree well with those previously reported $[21,22]$.

High resolution transmittance electron microscope: HRTEM was further used to obtain more information about the size and uniformity of the synthesized complexes in details. HR-TEM micrographs and electron diffraction of uncoated $\mathrm{Fe}_{3} \mathrm{O}_{4}$ nanoparticles are shown in Figure 2. Uncoated $\mathrm{Fe}_{3} \mathrm{O}_{4}$ appears spherical shape with narrow particle size distribution $(\sim 10 \mathrm{~nm})$. Otherwise, selective area electronic diffraction pattern (SAED) indicated the polycrystalline nature of these $\mathrm{Fe}_{3} \mathrm{O}_{4}$ nanoparticles (inset of Figure 2D). As shown in Figure 2 some uncoated $\mathrm{Fe}_{3} \mathrm{O}_{4}$ had formed clusters, this is in accordance to previous observation made by Gupta et al. [23]. This is proposed to be due to the absence of coating materials in the presence of aerobic conditions during their synthesis could enhance the hydrophobic interactions between the particles, thereby agglomerating them to form some clusters. After coating $\mathrm{Fe}_{3} \mathrm{O}_{4}$ nanoparticles with PVA, HR-TEM images in Figure 3 shows polydispersed particles with agglomeration attributed to magnetic dipole-dipole attractions between the particles, as observed in the $\mathrm{Fe}_{3} \mathrm{O}_{4}$ nanoparticles. Figure 4 Shows HR-TEM images of 6-Mercaptopurine loaded PVA-coated $\mathrm{Fe}_{3} \mathrm{O}_{4}$ nanoparticles with blurring film, confirming the loading of the drug onto the PVAcoated $\mathrm{Fe}_{3} \mathrm{O}_{4}$ surface.

FTIR spectra: FTIR was further performed within the wavelength range $4000-600 \mathrm{~cm}^{-1}$ to examine the mode of attachment of the PVA to the $\mathrm{Fe}_{3} \mathrm{O}_{4}$ and conjugation of 6-MP anticancer drug with the PVA coated $\mathrm{Fe}_{3} \mathrm{O}_{4}$. The most important IR spectral bands frequencies $(\mathrm{cm}$ $\left.{ }^{1}\right)$ were assigned according to Smith [24] and are cited in Table 1.
Inspection of the IR spectral data shows that:

- The broad band of uncoated $\mathrm{Fe}_{3} \mathrm{O}_{4}$ and PVA-coated-Fe $\mathrm{O}_{4}$ at 590 and $580 \mathrm{~cm}^{-1}$, respectively, is attributed to the stretching vibration of $(\mathrm{M})$ of $\mathrm{Fe}_{\mathrm{td}}-\mathrm{O}-\mathrm{Fe}_{\mathrm{Oh}}$, where $\mathrm{Fe}_{\mathrm{td}}$ and $\mathrm{Fe}_{\mathrm{Oh}}$ correspond to the iron occupying the tetrahedral and octahedral positions, respectively [25].

- The broad bands of pure 6-MP at 1615 and $1405 \mathrm{~cm}^{-1}$ are assigned to the stretching vibration frequency of $\mathrm{C}-\mathrm{C}$ group $(v \mathrm{C}=\mathrm{C})$ and the stretching vibration of $\mathrm{C}-\mathrm{N}$ group $(v \mathrm{C}-\mathrm{N})$, respectively. While the broad band appeared at $1270 \mathrm{~cm}^{-1}$ is due to the stretching vibration of $\mathrm{C}=\mathrm{S}$ group $(\nu \mathrm{C}=\mathrm{S})$. Furthermore, the band of pure 6-MP located at $3430 \mathrm{~cm}^{-1}$ is corresponding to the stretching vibration of $\mathrm{NH}$ group [26]. This confirmed the successful coating of $\mathrm{Fe}_{3} \mathrm{O}_{4}$ with PVA polymer.

- The FTIR spectra of 6-MP-loaded-PVA-coated- $\mathrm{Fe}_{3} \mathrm{O}_{4}$ showed that the vibrations of the stretching bands $\left(v_{\mathrm{C}-\mathrm{N}}\right.$, and $\left.v_{\mathrm{C}=\mathrm{S}}\right)$ are shifted to lower frequencies upon loading into PVA-coated- $\mathrm{Fe}_{3} \mathrm{O}_{4}$.

These observations can be taken as evidence for the success of loading process and it can be concluded that PVA-coated- $\mathrm{Fe}_{3} \mathrm{O}_{4}$ nanoparticles are interacted through the $\mathrm{C}=\mathrm{N}$ and the $\mathrm{C}=\mathrm{S}$ groups represented as:<smiles></smiles>
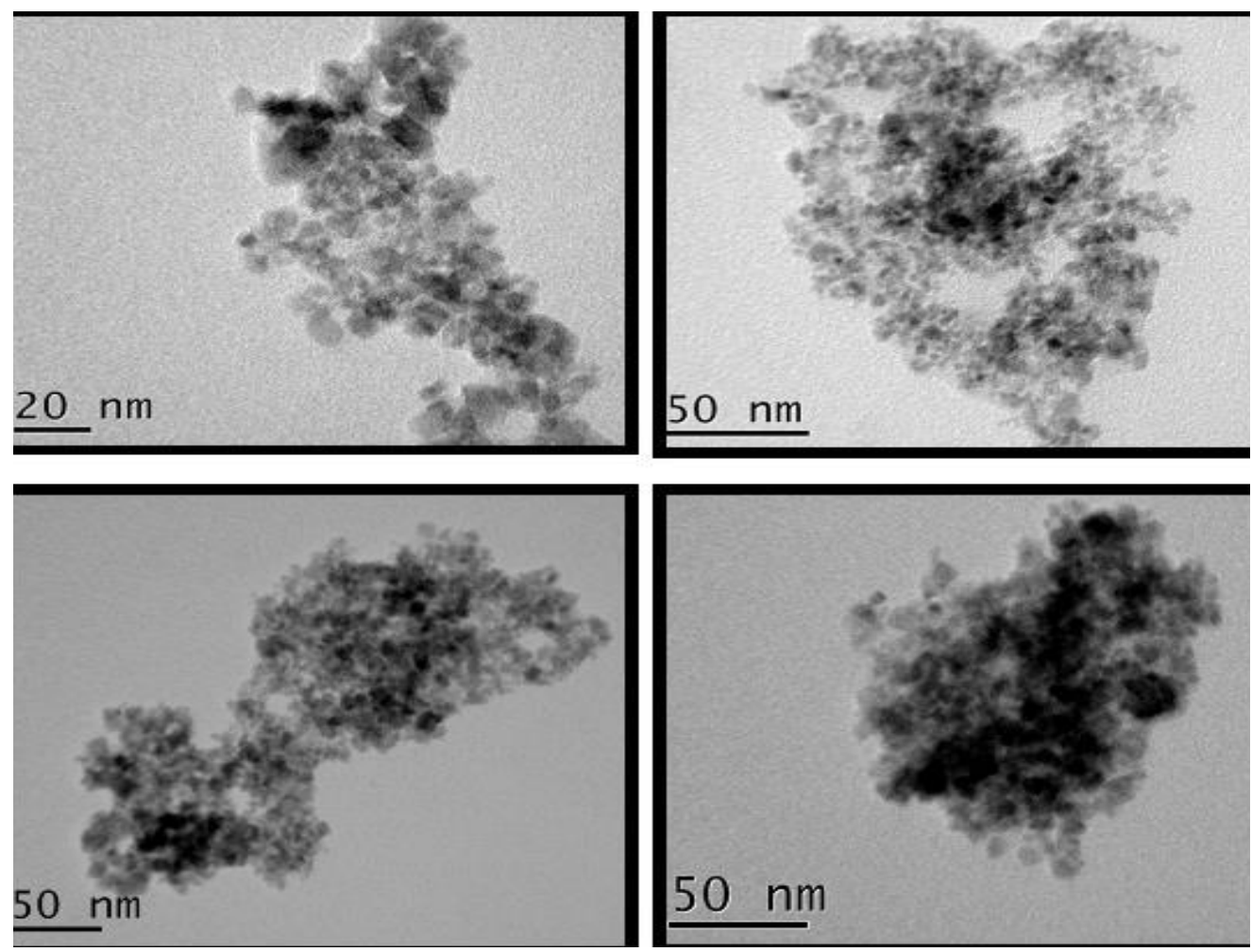

Figure 4: HR-TEM images from different spots with different magnification scales for 6-MP-PVA-coated magnetite nanoparticles. 
Citation: Moustafa ME, Amin AS, Magdi Y (2018) Cytotoxicity of 6-Mercaptopurine via Loading on PVA-Coated Magnetite Nanoparticles Delivery System: A New Era of Leukemia Therapy. J Nanomed Nanotechnol 9: 521. doi: 10.4172/2157-7439.1000521

Page 6 of 8

Thermogravimetric analysis: Herein, TGA was recorded from ambient temperature to $650^{\circ} \mathrm{C}$. The TGA curve of uncoated $\mathrm{Fe}_{3} \mathrm{O}_{4}$ nanoparticles in nitrogen atmosphere at $10^{\otimes} \mathrm{C} / \mathrm{min}$ ascending temperature rate showed no significant weight loss till $600^{\circ} \mathrm{C}$, indicating the thermal stability of the prepared nanoparticles, as previously recorded by other reports [27]. On the other hand, significant weight losses areas in the TGA curves of PVA-coated- $\mathrm{Fe}_{3} \mathrm{O}_{4}$ nanoparticles were observed through three degradation steps at the temperatures $152^{\circ} \mathrm{C}, 233^{\circ} \mathrm{C}$, and $445^{\circ} \mathrm{C}$; (Figure $5 \mathrm{a}$ ). The first step (of about $3 \%$ weight loss) is due to the loss of physically adsorbed water molecules while the second is attributed to loss of coordinated water molecules and the dehydration reaction of $-\mathrm{OH}$ groups in PVA polymer chains. The third step (of about $22 \%$ weight loss) is due to polymer (PVA) degradation on the surface of $\mathrm{Fe}_{3} \mathrm{O}_{4}$ nanoparticles. Overall trends of the TGA curves observed in uncoated $\mathrm{Fe}_{3} \mathrm{O}_{4}$ and PVA-coated- $\mathrm{Fe}_{3} \mathrm{O}_{4}$ nanoparticles were in agreement with those reported in the literature $[20,28]$.

For 6-MP-loaded-PVA-coated- $\mathrm{Fe}_{3} \mathrm{O}_{4}$, the thermal behavior indicates two stages of weight loss (Figure 5b). The first at $235^{\circ} \mathrm{C}$, with a total weight loss of $8 \%$, is attributed to dehydration of coordinated water molecules. The second step of thermal degradation (with a weight loss of about $10.7 \%$ ) was observed at $385^{\circ} \mathrm{C}$ which is due to decomposition of and 6-MP-PVA-coated $\mathrm{Fe}_{3} \mathrm{O}_{4}$ nano-composite.

Magnetic properties: Super paramagnetic materials play an important role in magnetic targeting and biomedical applications [29]. Figure 6a-6c shows the hysteresis loops for uncoated $\mathrm{Fe}_{3} \mathrm{O}_{4}$ nanoparticles, $\mathrm{Fe}_{3} \mathrm{O}_{4}$ nanoparticles coated with PVA and 6-MPPVA-coated $\mathrm{Fe}_{3} \mathrm{O}_{4}$ nano-composite which were characterized using a vibrating sample magnetometer at room temperature. Remanence and coercivity are absent in the hysteresis curves indicating that magnetic nanoparticles are super paramagnetic. The maximum value of saturation magnetization (Ms) for uncoated $\mathrm{Fe}_{3} \mathrm{O}_{4}$ is $56.9 \mathrm{emu} / \mathrm{g}$ around applied field strength of $10 \mathrm{kOe}$. This value is lower than that of bulk magnetite $(92 \mathrm{emu} / \mathrm{g})$ reported by Zhang et al. and Guardiaa et al. [30] and Guardiaa et al. [31]. This reduction corresponds to the decrease in particle size. In addition, $\mathrm{Ms}$ of uncoated $\mathrm{Fe}_{3} \mathrm{O}_{4}$ (Figure 6a) has a lower value than that of $\mathrm{Fe}_{3} \mathrm{O}_{4}$ nanoparticles coated with PVA 64.4 $\mathrm{emu} / \mathrm{g}$, this is in accordance to previous studies [32-34]. This proves the existence of PVA coats on the surface of $\mathrm{Fe}_{3} \mathrm{O}_{4}$ nanoparticles, which causes the exchange of electrons between the surface of $\mathrm{Fe}$ atoms and the coating polymers [35]. As expected, a further remarkable decrease in the Ms to $35.868 \mathrm{emu} / \mathrm{g}$ after loading 6-MP drug into PVA-coated$\mathrm{Fe}_{3} \mathrm{O}_{4}$ nanoparticles was observed, but the magnetic behavior remains unchanged. This may be due to the incorporation of both PVA and 6-MP on the surface of $\mathrm{Fe}_{3} \mathrm{O}_{4}$ nanoparticles.

The observed superparamagnetic property at room temperature of the prepared uncoated $\mathrm{Fe}_{3} \mathrm{O}_{4}$ nanoparticles, PVA-coated and 6-MP-

\begin{tabular}{|c|c|c|}
\hline Sample & IR frequency $\left(\mathrm{cm}^{-1}\right)$ & Assignment \\
\hline \multirow{3}{*}{ Uncoated $\mathrm{Fe}_{3} \mathrm{O}_{4}$} & 3420 & $v(\mathrm{H}-\mathrm{O})$ \\
\hline & 1625 & $\delta(\mathrm{H}-\mathrm{O}-\mathrm{H})$ of adsorbed water \\
\hline & 590 & $v\left(\mathrm{M}_{\mathrm{Th}}-\mathrm{O}-\mathrm{M}_{\mathrm{Oh}}\right)$ \\
\hline \multirow{7}{*}{ PVA-coated- $\mathrm{Fe}_{3} \mathrm{O}_{4}$} & 3430 & $v(\mathrm{H}-\mathrm{O})$ \\
\hline & 2910 & $v(\mathrm{C}-\mathrm{H})$ \\
\hline & 1630 & $1624 \delta(\mathrm{H}-\mathrm{O}-\mathrm{H})$ \\
\hline & 1420 & $v(C-C)$ \\
\hline & 1065 & $\mathrm{v}(\mathrm{M}-\mathrm{O}-\mathrm{C}(\mathrm{M}=\mathrm{Fe}))$ \\
\hline & 865 & $\mathrm{CH}_{2}$ rocking \\
\hline & 580 & $v\left(M_{t d}-O-M_{O h}\right)$ \\
\hline \multirow{4}{*}{ Pure 6-MP } & 3430 & v N-H \\
\hline & 1615 & $\vee C=C$ \\
\hline & 1405 & v C-N \\
\hline & 1270 & $\vee C=S$ \\
\hline \multirow{3}{*}{ 6-MP-PVA-coated- $\mathrm{Fe}_{3} \mathrm{O}_{4}$} & 3430 & v N-H \\
\hline & 1620 & $\vee \mathrm{C}=\mathrm{C}$ \\
\hline & 1410 & v C-N \\
\hline
\end{tabular}

Table 1: Assignment of FTIR spectral bands of uncoated $\mathrm{Fe}_{3} \mathrm{O}_{4}, \mathrm{PVA}$ coated iron oxide, pure 6-MP and 6-MP -conjugated PVA coated Fe $\mathrm{O}_{4}$
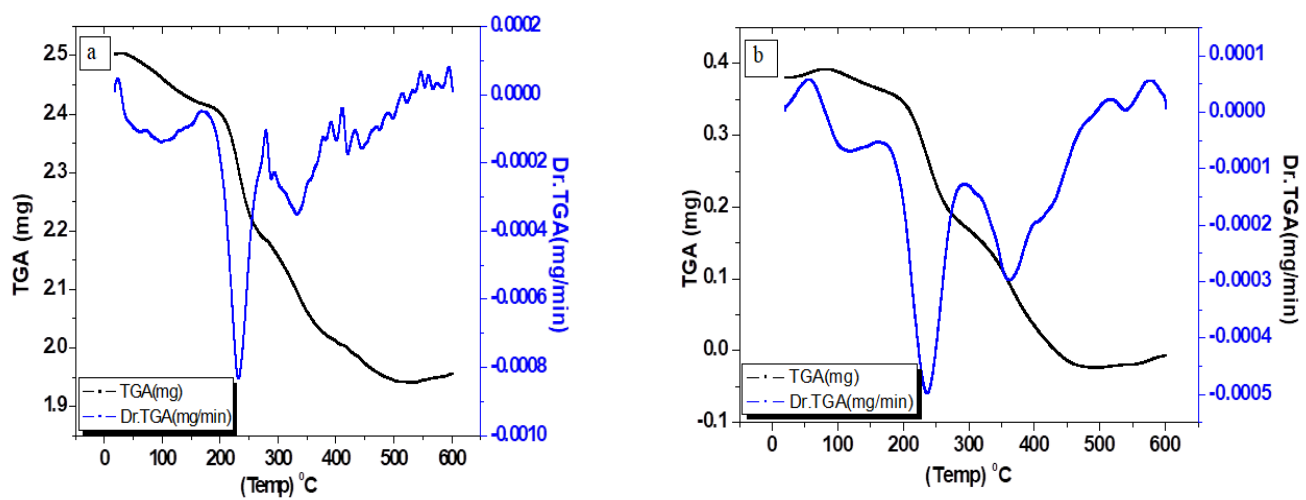

Figure 5: The TGA and Dr. TGA curves for (a) PVA coated $\mathrm{Fe}_{3} \mathrm{O}_{4}$ nanoparticles and (b) 6-MP-PVA-coated Fe $\mathrm{O}_{4}$ nanoparticles 

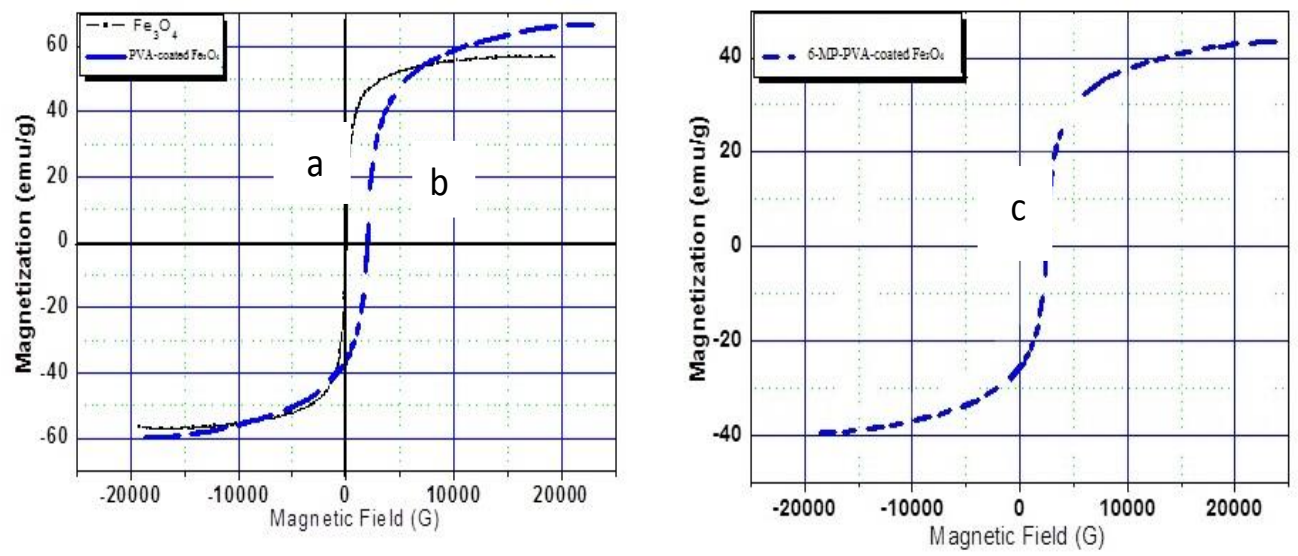

Figure 6: The relationship between the applied magnetic field $(\mathrm{H})(\mathrm{Oe})$ and the magnetism $(\mathrm{M})(\mathrm{emu} / \mathrm{g})$ for $\mathrm{Fe}_{3} \mathrm{O}_{4}(\mathrm{a}), \mathrm{PVA}^{-c o a t e d ~ F e} \mathrm{O}_{4}$ (b) and 6-MP loaded $\mathrm{Fe}_{3} \mathrm{O}_{4}$ (c)
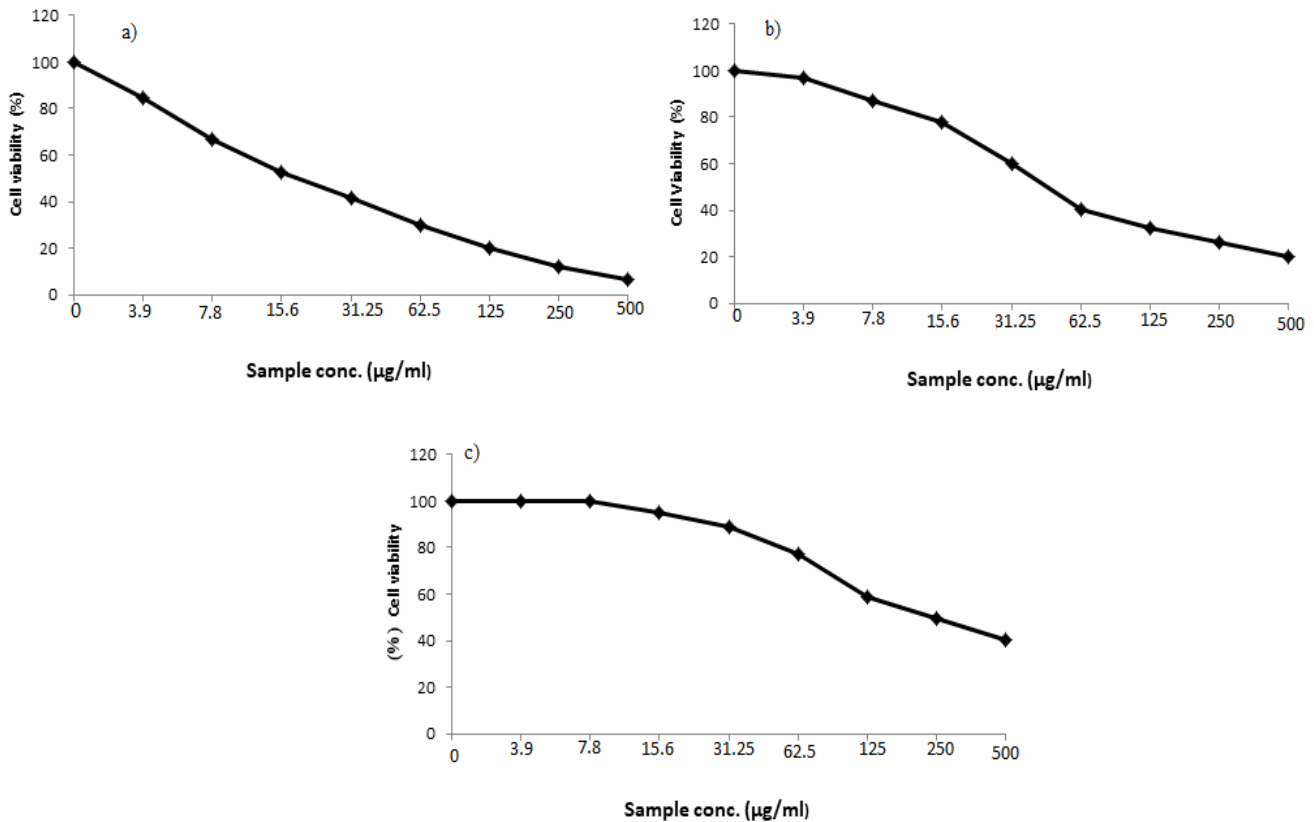

Figure 7: Plot of $(\%)$ cell viability against sample concentration $(\mu \mathrm{g} / \mathrm{mL})$ for (a) 6-MP-PVA-coated Fe $\mathrm{O}_{4}$ nanoparticles, (b) pure drug 6-MP, and (c) PVA-coated- $\mathrm{Fe}_{3} \mathrm{O}_{4}$ nanoparticles in $\mathrm{HL}-60$ cell line incubated for 24 hours at $37^{\circ} \mathrm{C}$ and $5 \% \mathrm{CO}_{2}$.

PVA-coated $\mathrm{Fe}_{3} \mathrm{O}_{4}$ nano-composite shows that they can successfully be delivered to the target site when these particles are guided magnetically. They also offer many other advantages such as they do not retain magnetism before and after removal of external magnetic field, which reduces the probability of particle aggregation due to magnetic dipole attraction [36].

In vitro biocompatibility study: The anti-leukemic effect of $\mathrm{Fe}_{3} \mathrm{O}_{4}$ nanoparticles coated with PVA, pure6-MP and 6-MP-PVA-coated $\mathrm{Fe}_{3} \mathrm{O}_{4}$ nano-composite was investigated in different concentrations to determine the $\mathrm{IC}_{50}$ values, against HL-60 cell line using a colorimetric assay following exposure for 24 hours. The plot of the percentage of cell viability versus the prepared samples concentration $(\mu \mathrm{g} / \mathrm{mL})$ is shown in Figure 7.

$\mathrm{Fe}_{3} \mathrm{O}_{4}$ nanoparticles coated with PVA did not show a significant decrease in the viability compared with untreated control cells at 24 hours post-treatment till the concentration of $125 \mu \mathrm{g} / \mathrm{mL}$. Thus the $\mathrm{IC}_{50}$ value of PVA-coated- $\mathrm{Fe}_{3} \mathrm{O}_{4}$ with $\mathrm{HL}-60$ was detected at a concentration of $142.5 \mu \mathrm{g} / \mathrm{mL}$. Furthermore, low percentage viability was observed among all used concentrations of 6-MP, with an $\mathrm{IC}_{50}$ value of $56.8 \mu \mathrm{g} /$ $\mathrm{ml}$. Our newly synthesized 6-MP-PVA-coated $\mathrm{Fe}_{3} \mathrm{O}_{4}$ nano-composite exhibited the highest cytotoxic effect on the leukemia cell line in a dose-dependent manner, the pattern of which resembles that for 6-MP or $\mathrm{Fe}_{3} \mathrm{O}_{4}$ nanoparticles coated with PVA (Figure 7). The $\mathrm{IC}_{50}$ value of 6-MP-PVA-coated $\mathrm{Fe}_{3} \mathrm{O}_{4}$ nano-composite with HL-60 was detected at a lower concentration of $14.9 \mu \mathrm{g} / \mathrm{mL}$, as compared to $\mathrm{IC}_{50}$ values of either 6-MP alone or $\mathrm{Fe}_{3} \mathrm{O}_{4}$ nanoparticles coated with PVA.

All the used concentrations of 6-MP in our study showed a significant inhibitory effect against HL-60 cell line. However, loading 
Citation: Moustafa ME, Amin AS, Magdi Y (2018) Cytotoxicity of 6-Mercaptopurine via Loading on PVA-Coated Magnetite Nanoparticles Delivery System: A New Era of Leukemia Therapy. J Nanomed Nanotechnol 9: 521. doi: 10.4172/2157-7439.1000521

Page 8 of 8

this low doses of 6-MP to $\mathrm{Fe}_{3} \mathrm{O}_{4}$ nanoparticles coated with PVA showed better anticancer activity. This demonstrates that $\mathrm{Fe}_{3} \mathrm{O}_{4}$ nanoparticles increase the drug delivery and only small traces of 6-MP are needed to give efficient anticancer activity upon loading on their surface.

The results suggested that our newly synthesized compound has better anticancer activity as compared to the pure 6-MP. This indicates the possibility of reduction the introduced dose of drug as well as dosing interval due to the sustained-release ability of the nanoparticles.

\section{Conclusions}

From our data of 6-MP-PVA-coated $\mathrm{Fe}_{3} \mathrm{O}_{4}$ nano-composite which is a model of incorporation of anticancer drug it was concluded that:

- Combinational $\mathrm{Fe}_{3} \mathrm{O}_{4}$ nanoparticles coated with PVA and 6-MP show much more effective anticancer activity and higher potency against HL-60 cell line than that of the drug alone because the nanoparticles increase the cellular up-take and enhance the activity of the drug.

- Minimize the dose of 6-MP drug and this lower the side effects of the drug.

- With the sustained release and possible targeted delivery potential of $\mathrm{Fe}_{3} \mathrm{O}_{4}$ nanoparticles coated with PVA, the least amount of 6-MP could be sufficient, hence reducing the dosing interval and unnecessary exposure to large quantities of this hazardous drug.

\section{References}

1. Sreeja V, Jayaprabha KN, Joy PA (2015) Water-dispersible ascorbic-acidcoated magnetite nanoparticles for contrast enhancement in MRI. Appl Nanosci 5: 435-441.

2. Alexiou C, Schmid RJ, Jurgons R, Kremer M, Wanner G, et al. (2006) Targeting cancer cells: magnetic nanoparticles as drug carriers. Eur Biophys J 35: 446-450.

3. Ang KL, Venkatraman S, Ramanujan RV (2007) Magnetic PNIPA hydrogels for hyperthermia applications in cancer therapy. Material Sci Eng C 27: 347-351.

4. Gupta AK, Gupta M (2005) Synthesis and surface engineering of iron oxide nanoparticles for biomedical applications. Biomaterials 26: 3995-4021.

5. Pankhurst QA, Connolly J, Jones SK, Dobson J (2003) Applications of magnetic nanoparticles in biomedicine. J Phys D: Appl Phys 36: R167.

6. Neuberger T, Schöpf B, Hofmann H, Hofmann M, Von Rechenberg B (2005) Superparamagnetic nanoparticles for biomedical applications: Possibilities and limitations of a new drug delivery system. J Magn Magn Mater 293: 483-496.

7. Jurgons R, Seliger C, Hilpert A, Trahms L, Odenbach S, et al. (2006) Drug loaded magnetic nanoparticles for cancer therapy. J Phys Condens Matter 18: S2893-S2902.

8. Ciofani G, Riggio C, Raffa V, Menciassi A, Cuschieri A (2009) A bi-modal approach against cancer: magnetic alginate nanoparticles for combined chemotherapy and hyperthermia. Med Hypotheses 73: 80-82.

9. Tietze R, Jurgons R, Lyer S, Schreiber E, Wiekhorst F, et al. (2009) Quantification of drug-loaded magnetic nanoparticles in rabbit liver and tumor after in vivo administration. J Magn Magn Mater 321: 1465-1468.

10. Alexiou C, Arnold W, Klein RJ, Parak FG, Hulin P, et al. (2000) Locoregional cancer treatment with magnetic drug targeting. Cancer Res 60: 6641-6648.

11. Wu W, He Q, Jiang C (2008) Magnetic iron oxide nanoparticles: synthesis and surface functionalization strategies. Nanoscale Res Lett 3: 397-415.

12. Wahajuddin, Arora S (2012) Superparamagnetic iron oxide nanoparticles: magnetic nanoplatforms as drug carriers. Int J Nanomedicine 7: 3445-3471.

13. Zhang Y, Kohler N, Zhang M (2002) Surface modification of super- paramagnetic magnetite nanoparticles and their intracellular uptake. Biomaterials 23: 15531561.

14. Cavalieri F, Chiessi E, Villa R, Viganò L, Zaffaroni N, et al. (2008) PVA-based hydrogel microparticles for doxorubicin delivery. Biomacromolecules 9: 1967 1973.

15. D'Souza AJM, Topp EM (2004) Release from polymeric prodrugs: linkages and their degradation. J Pharm Sci 93: 1962-1979.

16. Polifka JE, Friedman JM (2002) Teratogen update: azathioprine and 6-mercaptopurine. Teratology 65: 240-261.

17. Bishop JB, Witt KL, Sloane RA (1997) Genetic toxicities of human teratogens Mutat Res 396: 9-43.

18. Schmiegelow K, Al-Modhwahi I, Andersen MK, Behrendtz M, Forestier E, et al. (2009) Methotrexate/6-mercaptopurine maintenance therapy influences the risk of a second malignant neoplasm after childhood acute lymphoblastic leukemia: results from the NOPHO ALL-92 study. Blood 113: 6077-6084.

19. Yang K, Peng H, Wen Y, Li N (2010) Re-examination of Characteristic FTIR Spectrum of Secondary Layer in Bilayer Oleic Acid Coated $\mathrm{Fe}_{3} \mathrm{O}_{4}$ Nanoparticles. Appl Sur Sci 256: 3093-3097.

20. Kayal S, Ramanujan R (2010) Doxorubicin loaded PVA coated iron oxide nanoparticles for targeted drug delivery. Mater Sci Eng C 30: 484-490.

21. Mahmoudi M, Simchi A, Imani M, Milani AS, Stroeve P (2008) Optimal design and characterization of superparamagnetic iron oxide nanoparticles coated with polyvinyl alcohol for targeted delivery and imaging. J Phys Chem B 112 : 14470-14481.

22. Dorniani D, Hussein MZ, Kura AU, Fakurazi S, Shaari AH, et al. (2013) Preparation and characterization of 6-mercaptopurine-coated magnetite nanoparticles as a drug delivery system. Drug Des Devel Ther 7: 1015-1026.

23. Smith L (1979) Applied infrared spectroscopy. John Wiley \& Sons, New York, USA.

24. Cornell RM, Schwertmann U (2003) The iron oxides: structure, properties reactions occurrence and uses. ( $2^{\text {nd }}$ edtn), Wiley- $\mathrm{VCH}$, Verlag $\mathrm{GmbH} \& \mathrm{Co}$. KGaA, Weinheim, Germany.

25. Skehan P, Storeng R, Scudiero D, Monks A, McMahon J, et al. (1990) New colorimetric cytotoxicity assay for anticancer-drug screening. J Natl Cancer Inst 82: $1107-1112$.

26. Kurchania R, Sachin S, Sawant, Ball RJ (2014) Synthesis and characterization of magnetite/polyvinyl alcohol core-shell composite nanoparticles. J Am Ceram Soc 97: 3208-3215.

27. Mohapatra S, Pramanik NK, Ghosh SK, Pramanik P (2006) Synthesis and characterization of ultrafine poly (vinylalcohol phosphate) coated magnetite nanoparticles. J Nanosci Nanotechnol 6: 823-829.

28. Qu JB, Shao HH, Jing GL, Huang F (2013) PEG-chitosancoated iron oxide nanoparticles with high saturated magnetization as carriers of 10-hydroxycamptothecin: preparation, characterization and cytotoxicity studies. Colloids Surf B Biointerfaces 102: 37-44.

29. Zhang JZ, Chen XY, Wang BN, Shi CW (2008) Hydrothermal Synthesis and Self-Assembly of Magnetite $\left(\mathrm{Fe}_{3} \mathrm{O}_{4}\right)$ Nanoparticles with the Magnetic and Electrochemical Properties. J Cryst Growth 310: 5453-5457.

30. Guardiaa P, Batlle-Brugala B, Rocab AG, Iglesiasa O, Moralesb MP, et al. (2007) Surfactant effects in magnetite nanoparticles of controlled size. J Magn Magn Mater 316: 756-759.

31. Jiang W, Yang H, Yang S, Horng H, Hung J, et al. (2004) Preparation and properties of superparamagnetic nanoparticles with narrow size distribution and biocompatible. J Magn Magn Mater 283: 210-214.

32. Cullity B (1955) Introduction to Magnetic Materials, Addison-Wesley, Reading, MA

33. Gomez-Lopera S, Plaza R, Delgado A (2001) Synthesis and characterization of spherical magnetite/biodegradable polymer composite particles. J Colloid Interface Sci 240: 40-47.

34. Ge Y, Zhang Y, Xia J (2009) Effect of surface charge and agglomerate degree of magnetic iron oxide nanoparticles on KB cellular uptake in vitro. Colloids Surf B Biointerfaces 73: 294-301.

35. Tartaj P, Morales MP, Gonzalez-Carreño T, Veintemillas-Verdaguer S, Serna CJ (2005) Advances in magnetic nanoparticles for biotechnology applications. Magn Magn Mate 28: 290-329.

36. Rana S, Gallo A, Srivastava RS, Misra RD (2007) On the suitability of nanocrystalline ferrites as a magnetic carrier for drug delivery: functionalization, conjugation and drug release kinetics. Misra Acta Biomater 3: 233-242. 